\title{
JOGOS ELETRÔNICOS NA PÓS- MODERNIDADE
}

Vítor de Morais Alves Evangelista, Rita Melissa Lepre, Aline Kadooka

Universidade Estadual Paulista - UNESP, Programa de Pós-Graduação em Psicologia, Assis, SP. FAPESP - Fundação de Amparo à Pesquisa do Estado de São Paulo. E-mail: vitordemorais@hotmail.com

\section{RESUMO}

Em um mundo caótico e hedonista, onde as relações são determinadas pela descartabilidade, mobilidade e rapidez, o virtual aparece como solução frente à ausência de sentido da realidade. Tendo em vista os poucos estudos relacionando os jogos eletrônicos, o presente artigo tem como objetivo proporcionar uma discussão acerca dos jogos eletrônicos, suas supostas influências nos jogadores e as possíveis ressonâncias na realização dos desejos frente às frustrações pósmodernas. Concluímos que a era do software e da individualidade propõe a superação de barreiras geográficas e temporais propiciando novas formas de socialização. Os jogos eletrônicos emergem como catarse da sociedade pós-moderna tendo como características principais a fuga, violência, liberdade e satisfação dos desejos tidos como impossíveis na realidade.

Palavras-chave: jogos eletrônicos, modernidade, pós-modernidade, virtual, realidade.

\section{ELECTRONIC GAMES IN POSTMODERNITY}

\begin{abstract}
In a chaotic and hedonistic world where relationships are determined by disposability, mobility and speed, the virtual front appears as a solution to the lack of sense of reality. Having the few studies linking video games in mind, this paper aims to provide a discussion of electronic games, their supposed influence on the players and possible resonances in the fulfillment of desires in the face of postmodern frustration. We conclude that the era of software and individuality proposes overcoming geographic barriers and time providing new forms of socialization. Electronic games emerge as catharsis of postmodern society and its main features to escape, violence, freedom and fulfillment of desires regarded as impossible in reality.
\end{abstract}

Keywords: electronic games, modernity, postmodernity, virtual, reality. 


\section{INTRODUÇÃO}

Em um mundo caótico, assolado pela peste e fome, Antonius Block, cavaleiro cruzado, se vê frente a frente com a personificação de sua finitude. Entretanto, a figura pálida da morte não parece assustá-lo tanto quanto suas incertezas existenciais: Deus, fé e toda a falta de sentido em sua vida. Diante da irremediável presença da morte, Block propõe a esta, sua indubitável certeza, um jogo de xadrez. Nessa belíssima e emblemática passagem do clássico filme O Sétimo Selo de Ingmar Bergman, de 1956, o jogo de xadrez torna-se uma alegoria, uma forma de burlar e adiar sua desconfortável realidade que joga com peças negras.

O mundo atribulado do século XIII, do qual faz parte Antonius Block, não diverge tão expressivamente do panorama contemporâneo. Embora o avanço tecnológico atinja patamares incrivelmente inimagináveis em outrora, ainda temos aqui alguns dos mesmos elementos que constituíam o ambiente medieval, intolerância religiosa, fome, doenças, guerras e a mesma busca desenfreada pelo sentido da vida, pela razão da existência. Uma vez que a vida humana atual está cada vez mais caracterizada pela, descartabilidade, mobilidade e rapidez, porque não dizermos que possuímos o mesmo hálito da finitude em nossos ombros, o mesmo que atormentava Block. Bauman (2001) caracteriza a atual sociedade como imersa em uma modernidade líquida, onde os indivíduos constantemente buscam suas identidades frente à instantaneidade do tempo e das relações, a era do software e individualidade. Giddens (1991) caracteriza a sociedade moderna direcionada ao contexto do virtual. A superação das barreiras geográficas e temporais propiciou o virtual como nova forma de socialização e parte integrante da atual constituição de uma sociedade individualista. Tal como na enigmática partida de xadrez de Antonius Block, o virtual é criado em um espaço peculiar, mais particularmente na relação entre jogador e jogo, onde se cria uma dimensão na qual o jogador imerge em um mundo com diferentes possibilidades, personalidades e poderes, um "oásis em meio às regras e convenções" da realidade. (MELLO E CASTRO, 2012, p.2). O objetivo do presente artigo é proporcionar uma discussão acerca dos jogos eletrônicos, suas supostas influências nos jogadores e as possíveis ressonâncias na realização dos desejos frente às frustrações pós-modernas.

\section{DO LÚDICO AO VIRTUAL}

O lúdico descrito magistralmente por Johan Huizinga em Homo ludens expõe o surgimento dos jogos como produtos culturais destinados a eliminar as tensões e dificuldades do cotidiano moderno, "como realidade objetiva, o desenlace do jogo é, por si, insignificante e indiferente"; o que verdadeiramente expressa de forma indiscutível a essência do jogo é que "algo está em jogo". 
(HUIZINGA, 1971. p. 67). Huizinga também descreve a importância do jogo no nascimento das culturas primitivas e a sua necessidade para a formação da cultura no estado em que a conhecemos hoje (GALLO, 2007).

Em Nietzsche, a interpretação do mundo, da vida e da existência como um jogo é a resposta a um modelo de universo desprovido de sentido. Este mundo é o cenário do jogo do criar, o âmbito do jogo que dá valor e marca o fim do domínio da razão. Esses testemunhos parecem nos indicar que o eminente pensador alemão, em $\mathrm{O}$ nascimento da Tragédia se serve fartamente da figura do jogo, porque ela constitui a forma suprema e mais valiosa da relação do homem com o mundo (GUERVÓs, 2004).

Os jogos eletrônicos, de acordo com a socióloga Fátima Aparecida Cabral (2004), "satisfazem desejos inconfessos, levando à catarse impulsos agressivos e violentos". O conceito de catarse, apropriadamente empregado, de origem aristotélica, parte das tragédias gregas e referese a uma ablução, ou purgação, dos sentimentos ou ações considerados censuráveis. Segundo Braga (2012) a catarse possibilitaria ao espectador atingir um estado interno onde ficaria exposta a natureza humana, "assim como um relâmpago ilumina uma paisagem, as emoções mostrariam a nós mesmos nossa própria natureza".

Segundo Cabral (2002), os jogos eletrônicos não podem ser vistos como simples passatempo, pois estes representam uma atividade lúdica voltada para a socialização, direcionando o jogador para diversas experiências. Para a autora os jogos eletrônicos possibilitam ao jogador sentir, mesmo que virtualmente, emoções que dificilmente poderão ser vivenciadas no mundo real. Ao jogador é oferecida a oportunidade de se afirmar frente a obstáculos, às limitações das capacidades e aos desejos, atingindo dessa forma a plenitude, artificialmente, de sentido na vida real. Trata-se, portanto, de encontrar uma forma de escape, uma oportunidade de evasão e distração.

Quando incorporado ao herói virtual, o indivíduo encontra-se provido de novas habilidades, a força sobre-humana, a capacidade de voar, características que permitem ao jogador vivenciar a ficção. Em tal relação com o personagem, supõe-se "que ao se colocar no lugar do personagem esse espaço ficcional torna-se mais imersivo e pode favorecer ainda mais a realização fantasmática do desejo", como em um sonho (RAMOS, 2009). Para Meira (2003) este sonho atualmente encontra-se caracterizado por imagens e expressões que conformam sua vida na promessa da felicidade. As crianças e adolescentes, principalmente, estão submetidos a um vigor hegemônico de uma formação social acrítica e anestesiadora. 
Como nas tragédias gregas elucidadas em a Poiética de Aristóteles, cuja narrativa é essencial a sedução do expectador, Mello e Castro (2012) ressaltam que sedução e imersão das narrativas nos games fizeram com que a indústria de jogos eletrônicos obtivesse o terceiro lugar em termos de importância na economia mundial, perdendo apenas para indústria bélica e automobilística, de acordo com dados da Associação Brasileira de Games - ABRAGAMES (2010). Kenski e Aguerre (2003) em matéria da revista Superinteressante, expõem que o poder imersivo e os constantes desafios impostos pelos jogos eletrônicos, são tão expressivos que algumas pesquisas, como a de Egenfeldt-Nielsene Smith, de 2003, indicam que vários jogadores são levado a um estado de experiência máxima denominada de flow, uma sensação só comum a esportistas de alta performance e monges em meditação, uma sensação onde os sentidos de tempo e espaço praticamente desaparecem. Daí o fato de serem gastos horas e até dias em jogos eletrônicos.

Eis o desafio dos produtores: jogos mais atraentes, dinâmicos, competitivos e reais resultam em jogos mais rentáveis. De acordo com o Serviço Brasileiro de Apoio às Micro e Pequenas Empresas, Sebrae, (2013) , o Brasil é o quarto maior mercado do mundo de jogos eletrônicos, com mais de 35 milhões de jogadores. Em 2012 a indústria de jogos eletrônicos movimentou cerca de $\mathrm{R} \$$ 5,3 bilhões (um aumento de 32\% em relação ao ano anterior). Já nos Estados Unidos, o mercado digital de jogos faturou US\$11,7 bilhões no ano passado, um aumento de $10 \%$ em relação ao ano passado. Na China, indústria de games da China faturou US\$ 13 bilhões de dólares em 2013, segundo relatório oficial. O maior responsável por esse faturamento foi a categoria de jogos online para computador, que arrecadou US\$ 8,7 bilhões. Os games para celular também tiveram uma grande participação.

\section{JOGOS E PÓS-MODERNIDADE}

Mas o que pode ser atraente na contemporaneidade, o que torna um jogo sedutor? Segundo o Superdata, site americano que mede o consumo de bens digitais, o jogo CrossFire, game de tiro da empresa sul-coreana SmileGate, faturou US\$ 957 milhões em 2013, tornando-se assim o jogo mais rentável do ano passado. Trata-se de um jogo tipo first personal shooter ou tiro em primeira pessoa onde os jogadores assumem o papel de um dos vilões da organização terrorista Black List ou das forças policiais da organização Global Risk, entrando numa batalha online da qual os jogadores têm de trabalhar em equipe para chegar ao objetivo de cada mapa ou missão. Os jogos em primeira pessoa seriam aqueles onde o jogador possui controle direto no jogo, ou seja, tem a impressão de estar no jogo através de um tipo de "câmera", na qual "a visão do jogador corresponde exatamente àquela que ele teria com o ponto de vista do seu próprio 
olho" (Alves, 2004, p. 37). Cunha (2008) ao expor a questão da busca da felicidade por intermédio do simulacro aponta para uma cultura do narcisismo onde é instalada a divisão radical do mundo entre vencedores e perdedores, tornando a felicidade um direito exclusivo dos primeiros enquanto os ditos vencidos são destinados ao ostracismo e à exclusão do jogo econômico e social, se tornando uma subespécie de restos da sociedade de consumo.

Há um grande apelo à violência em grande parte dos jogos e Cabral (2004) ressalta a exposição aos jogadores e o desprezo com certos caráteres sócio-históricos e as qualidades e virtudes humanas. A naturalização da violência, sua justificativa e sua lógica brutal aparecem nos jogos eletrônicos como fundamentais ao processo de desumanização que ocorre com o império da força física, e esta se apresenta como a qualidade fundamental dos seres virtuais. Atualmente a maioria das crianças que, desde muito cedo, participam e sofrem com a realidade emocional e social do mundo adulto, tendem a substituir o mundo da fantasia criadora, tão própria e característica da infância, pelo mundo do simulacro. A autora ainda afirma que através das brincadeiras tradicionais, as crianças aprendiam, que o processo construtivo estava ligado a ideia de desconstrução, mudança e transformação, já com o advento dos jogos eletrônicos, as crianças alienam-se em atividades lúdicas onde empregam cada vez menos seus sentidos.

Seber (1997) alega que eles permitem compreender os diferentes papéis sociais e o contexto no qual a criança está inserida como também oferece oportunidade para compreensão das suas experiências favorece o processo de socialização. O jogo deve ser considerado como forma de socialização, considerando que ao representar papéis e lidar com regras, a criança está sendo preparada para ocupar um lugar na sociedade adulta o que favorece, por exemplo, a aquisição de valores. Segundo Abreu (2003, p.02) a "áurea má dos jogos é um tanto óbvia". Como tudo o que gera prazer no homem. Estudo publicado em 2009 sobre as implicações dos jogos eletrônicos no desenvolvimento moral em adolescentes, por Daniela Karine Ramos, na revista eletrônica do Programa de Pós-Graduação em Comunicação da Universidade Federal Fluminense, Ciber legenda identificou que o ambiente virtual proporcionado pelos games se constituem como espaços de ausência da moral e locais de realização fantasmática de desejos. Os adolescentes pesquisados vivenciam nos jogos papéis e comportamentos que não poderiam ser tolerados na vida real através de avatares com características de acordo com o seu ideal.

\section{CONSIDERAÇÕES FINAIS}

Bauman (2001) utiliza a ideia de liquidez em oposição à solidez, uma metáfora apropriada da primeira modernidade. Tal liquidez estaria invadindo todos os setores da modernidade que 
antes eram tidos como sólidos. O indivíduo torna-se cada vez mais apto a escolher, dentre as opções dispostas pelo mercado ao consumo. Embora as possibilidades de escolha sejam infindas, isso não faz dos indivíduos pessoas mais felizes, pois, as consequências de uma má escolha tendem a recair sobre o indivíduo de forma fulminante, visto a não existência de bases sólidas nas quais se pode apoiar. Com os avanços no plano técnico e teórico, a humanidade passou a acreditar que percorria uma linha contínua em direção ao desenvolvimento e a certeza divina foi substituída pela certeza na razão científica ou o desencantamento do mundo (GIDDENS, 1991).

Com o surgimento das novas formas de socialização, consequência do surgimento da era do software e a ruptura das barreiras geográficas e temporais, os jogos eletrônicos emergem como catarse da sociedade pós-moderna, tendo como características principais a fuga, violência e liberdade, ou seja, a satisfação dos desejos tidos, muitas vezes, como impossíveis de serem realizados na realidade.

\section{REFERÊNCIAS}

ABRAGAMES. Associação Brasileira de Games. 2010. Disponível em http://brasileconomico.ig.com.br/noticias/mercado-de-games-explode-no-brasil_137817.html, Acessado em 13 de Fevereiro de 2014.

ABREU, A.. Videogame: um bem ou um mal? Um breve panorama da influência dos jogos eletrônicos na cultura individual e coletiva. André de Abreu: jornalismo e internet para quem usa. São Paulo, 2003.

ALVES, L. Game over: jogos eletrônicos e violência. Tese (Doutorado em Educação). Programa de pós-graduação em educação. Universidade Federal da Bahia, 2004.

BAUMAN, Z. Modernidade Líquida. Rio de Janeiro: Jorge Zahar, 2001.

BERGMAN, I. O Sétimo Selo. 1956.

BRAGA, E. C. Catarse: o corpo, seus rituais e cerimônias na arte contemporânea, 2012. Disponível em http://www.edubraga.pro.br/art-design/o-corpo-seus-rituais-e-cerimonias-em-catarse-naarte-contemporanea/. Acessado em 14 de Fevereiro de 2014.

CABRAL, F. Entrevista. In 4ạ Cúpula Mundial de Mídia para Crianças e Adolescentes. Rio de Janeiro: Multirio, 2004.

Jogos eletrônicos: técnica ilusionista ou emancipadora? Revista USP: "Dossiê Informática/Internet", São Paulo, n. 35, p.134-145, 2002.

CUNHA, E. L. A felicidade no registro do simulacro. IV ENECULT - Encontro de Estudos Multidisciplinares em Cultura, Salvador, 2008. 
EGENFELDT-NIELSEN, S.; SMITH, J.H. Playing With Fire: How do computer games affect the player? Report for The Media Council for Chilren and Young People. September 2003.

G1. TECNOLOGIA E GAMES. "Crossfire" é game gratuito que mais faturou em 2013, diz pesquisa. 2013. Disponível em http://g1.globo.com/tecnologia/games/noticia/2014/01/crossfire-e-gamegratuito-que-mais-faturou-em-2013-diz-pesquisa.html. Acessado em 19 de

Fevereiro de 2014.

GALLO, S.N. Jogo Como Elemento da Cultura: aspectos contemporâneos e as modificações na experiência do jogar. Tese (Doutorado em Comunicação) Programa de pós-graduação me comunicação. PUC - São Paulo, 2007.

GIDDENS, A. As Consequências da Modernidade. São Paulo: Ed UNESP, 1991, 2a ed.

GUERVÓS, L. E. Arte y poder. Aproximación a la estética de Nietzsche, Madrid: Editorial Trotta, 2004. ISBN: 84-8164-611-3.

HUIZINGA, J. Homo ludens: o jogo como elemento da cultura. 6. ed. São Paulo: Perspectiva, 1971.

KENSKI, R.; AGUERRE, G.; MAROJA, R. Armas de diversão em massa. Superinteressante, São Paulo: Junho, 2003.

MEIRA, A. M. Inteligência Artificial. Correio da APPOA, n. 95, POA, 2003.

MELLO, H., CASTRO, C. Ludosfera: o espaço lúdico virtual. Intercom - Sociedade Brasileira de Estudos Interdisciplinares da Comunicação. XXXV Congresso Brasileiro de Ciências da Comunicação - Fortaleza, CE, 2012.

RAMOS, D. K. Mundo virtual dos games: implicações sobre o desenvolvimento moral. Ciber Legenda, Universidade Federal fluminense, 2009.

SEBER, M.G. Psicologia do pré-escolar: uma visão construtivista. São Paulo: Moderna , 1997.

SEBRAE. O panorama e a evolução do mercado de "Games" no Brasil, 2013. 